\title{
A IMPORTÂNCIA DA MEDITAÇÃO PARA O ENSINO DE QUÍMICA
}

\author{
THE IMPORTANCE OF MEDITATION FOR TEACHING CHEMISTRY
}

\author{
Rafael Soares Silva ${ }^{1}$
}

RESUMO: O presente artigo teve por objetivo pesquisar e refletir sobre a influência das práticas de meditação no ensino de química, como essa ferramenta pode auxiliar no maior desempenho dos estudantes, a partir da otimização das técnicas de memorização, concentração e estabilidade emocional. O ensino da química ainda é amparado em métodos tradicionais de ensino, que tornam essa ciência de difícil compreensão, desta forma, uma matéria com relações de aprendizagens moldadas por dificuldades e que, em casos extremos, estabelece uma relação de repulsa discente. Nesse contexto, a meditação se constitui como um elemento do conjunto de Práticas Integradas em Saúde (PICs) com diversos benefícios dentro dos mais variados ambientes, tais como aumento do foco, criatividade, estimulação à memória, reducação de conflitos e outros. Essa pesquisa possui uma metologia qualitativa (LUDCKE; ANDRE, I986), alicerçada, sobretudo, na teoria sociointeracionista de Vygotsky (199I) sobre as relações entre aprendizagem e desenvolvimento, refletindo sobre a união dos aspectos intelectuais e os afetivos nesse processo. $O$ estudo revelou que a aplicação da meditação no ambiente escolar mostra-se como um forte instrumento para o ensinoaprendizagem de química, uma vez que essa ferramenta pode auxiliar no maior desempenho dos estudantes, a partir da otimização das técnicas de memorização, concentração e estabilidade emocional.

Palavras-chave: Ensino de Química. Práticas Integradas em Saúde. Meditação.

ABSTRACT: This article aimed to research and reflect on the influence of meditation practices on chemistry teaching, as this tool can help improve student performance by optimizing memorization techniques, concentration and emotional stability. Chemistry teaching is still supported by traditional teaching methods, which make this science difficult to understand, thus, a subject with learning relationships shaped by difficulties and which, in extreme cases, establishes a relationship of student disgust. In this context, meditation constitutes an element of the set of Integrated Health Practices (PICs) with several benefits within the most varied environments, such as increased focus, creativity, memory

${ }^{I}$ Pós- doutorando em Química pelo IQSC-USP; Pós-doutor em Educação, Contextos Contemporâneos e Demandas Populares (UFRRJ); Doutor em Ensino de Ciências e Matemática. Mestre em Engenharia e Ciências dos Materiais (MACKENZIE); Licenciado em Química, Biologia e Pedagogia. Membro do Observatório de Educação Especial e Inclusão - OBEE - UFRRJ.

https://orcid.org/oooo-ooor-9994-6653. http://lattes.cnpq.br/o828666762650747

E-mail:doc.rafaelsoares@gmail.com. 
stimulation, conflict reduction and others. This research has a qualitative methodology (LUDCKE; ANDRE, 1986), based, above all, on Vygotsky's (1991) socio-interactionist theory on the relationship between learning and development, reflecting on the union of intellectual and affective aspects in this process. The study revealed that the application of meditation in the school environment proves to be a strong instrument for teaching and learning chemistry, as this tool can help improve student performance by optimizing memorization, concentration and emotional stability.

Keywords: Chemistry teaching. Integrated Health Practices. Meditation.

\section{INTRODUÇÃO}

Atualmente, ainda se desenvolve uma metodologia de memorização que muito pouco relaciona a Química com o cotidiano do aluno. Apesar desse ensino tradicional ainda perdurar, novas concepções metodológicas estão trazendo outros olhares sobre o Ensino de Química.

Pesquisas propondo contribuições ao Ensino de Química demonstram, muitas vezes, o fato de adisciplina ser apresentada com complexidade e sem articulação do contexto do estudante com os componentes de outras áreas do conhecimento, dificultando a aprendizagem e a permanência dos estudantes nas escolas (SILVA, 2020; 2021).

A partir dessa visão, as novas concepções metodológicas que surgem, apontam para um Ensino de Química que promete fornecer aos estudantes os mecanismos que lhes possibilitem ter outra dimensão dessa ciência. Nesse cenário, a meditação vem surgindo como uma prática pedagógica que possibilita o aperfeiçoamento das técnicas de memorização, atenção e concentração dos discentes.

A princípio, a grande importância em se estudar Química está na possibilidade de conhecer melhor o ambiente no qual vivemos e as novas descobertas científicas que afetam diretamente ou indiretamente nossas vidas. Os conhecimentos químicos auxiliam o ser humano a fazer um melhor aproveitamento dos materiais e a viver melhor, sem prejudicar nem destruir o meio ambiente (LIMA, 2012).

Por outro lado, diversos problemas têm sido observados no Ensino de Química, tais como: aprendizagem restrita a baixos níveis cognitivos, ensino extremamente centrado no professor com aulas predominantemente expositivas, ausência de experimentação, falta de 
relação do conteúdo com o cotidiano e livros didáticos que enfatizam a transmissão de informações memorizáveis e não a construção do conhecimento (MARCONDES; PEIXOTO, 2007).

Para se tornar efetivo, o Ensino de Química deve ser problematizador, desafiador e estimulador, de maneira que seu objetivo seja o de conduzir o estudante à construção do saber científico. É preciso que o conhecimento químico seja apresentado ao aluno de uma forma que possibilite interagir ativa e profundamente com o seu ambiente, entendendo que esse faz parte de um mundo do qual ele também é ator e corresponsável.

Nessa perspectiva, Vygotsky levantou a questão da relação entre ensino, aprendizagem escolar e desenvolvimento cognitivo. Na teoria sociointeracionista de Vygotsky as relações entre aprendizagem e desenvolvimento são aspectos muito importantes, pois para ele o desenvolvimento é promovido pela aprendizagem, e a interação entre meio e indivíduo é essencial nesse processo (VYGOTSKY, I991).

A aprendizagem pode se dar em três domínios principais diferentes:

I) Físico: ligado aos cinco sentidos, visão, audição, tato, paladar e olfato;

2) Cognitivo: relacionado a como a pessoa pensa e aprende;

3) Emocional: refere-se à forma como o indivíduo se sente em termos psicológicos e fisiológicos.

Mais recentemente, incorporado no mesmo nível de relevância, um quarto domínio, a metacognição. $\mathrm{O}$ conceito de metacognição está relacionado ao ato de pensar sobre o próprio pensamento, onde a reflexão e a autoconsciência sobre a maneira como se aprende tornam-se, progressivamente, mais importantes do que o próprio ato de aprender.

A prática da meditação impacta em todo processo educacional, favorecendo a aprendizagem como um todo. Mesmo assim, o domínio metacognitivo é, provavelmente, aquele que é mais relevante.

À medida que a metacognição vai assumindo destaque, a importância de se levar em conta as possibilidades de exercícios de meditação acoplados à aprendizagem faz cada vez mais sentido. A prática de meditação promove transformações que auxiliam na capacidade de 
foco, em regular emoções, reduzir ansiedades e entender melhor seu contexto e as pessoas ao seu redor.

Vygotsky critica a separação, enquanto objeto de estudo, entre os aspectos intelectuais e os afetivos. Sua abordagem holística para a dinamização do processo de ensino e aprendizagem propõe a existência de um sistema dinâmico de significados em que o afetivo e o intelectual se unem e se inter-relacionam: são as necessidades e impulsos de uma pessoa que direcionam seus pensamentos, ao mesmo tempo em que são seus pensamentos que impulsionam seu comportamento e sua atividade (VYGOTSKY, I999).

Dentre as novas propostas metodológicas do ensino básico, apresenta-se a meditação como técnica que favore o processo cognitivo. Ao trabalhar o aspecto emocional reduz-se a ansiedade e contempla a concepção de educação holística, a qual acredita-se que seja possível desenvolver, na sala de aula, um ambiente integrador que permita expandir outros aspectos do aluno como o seu lado emocional, artístico, sensível ou ainda espiritual (YUS, 2002).

O presente artigo teve por objetivo pesquisar e refletir sobre a influência das práticas de meditação no Ensino de Química, e como essa ferramenta pode auxiliar em um maior desempenho dos estudantes, a partir da otimização das técnicas de memorização, concentração e estabilidade emocional.

Metodologicamente, trata-se de um levantamento bibliográfico sobre a importância da meditação no Ensino teórico de Química. Os artigos pesquisados estão indexados na base de dados Literatura Latino-Americana e do Caribe em Ciências da Saúde (LILACS), Periódico da Coordenação de Aperfeiçoamento de Pessoal de Nível Superior (Capes), Google Acadêmico e Scientific Electronic Library Online (Scielo). Essa pesquisa possui uma metologia qualitativa a partir da discussão de teoricos como: LUDCKE; ANDRE, 1986; ROCHA; FLORES; MARQUÊS, 2015; COSSIA; DE ANDRADE, 2020, entre outros, alicerçada, sobretudo, na teoria sociointeracionista de Vygotsky (199I). Nesse contexto, elaborou-se a seguinte questão norteadora: de que modo, a meditação potencializa os processos de ensino e aprendizagem do compoente de Química?

Esta pesquisa, justifica-se pela análise da falta de materiais que explanam sobre o uso da metitação, dentro do currículo de Química; e pela necessidade desse conhecimento para a efetivação do uso das metodologias ativas do novo ensino desse componente, levando em consideração os desafios da atuação como professor de ciências. 


\section{RELAÇÕES ENTRE APRENDIZAGEM, MEMÓRIA E ATENÇÃO NO ENSINO}

A memória e aprendizagem são termos que estão fundamentalmente interligados. A memória humana é um elemento fundamental nas tarefas de compreensão verbal e escrita, no cálculo e raciocínio. Ela representa um papel indispensável no sistema cognitivo e poderá ser considerada responsável por algumas diferenças importantes ao nível do desempenho dos sujeitos nas tarefas escolares, profissionais, do dia a dia, na execução e performance das tarefas a realizar.

Os autores Baddeley, Anderson e Eysenck (20II) trazem um conceito mais completo sobre a memória, a qual pode ser entendida como um sistema multicomplexo que se combina por uma estrutura de arranjos de codificações ou subsistemas, os quais proporcionam as funções elementares da memória: o armazenamento de informações e a recuperação delas no cérebro.

O cérebro utiliza de um arcabouço de informações para proporcional o resgate de memórias. Essa estrutura básica obedece e pode ser categorizada a partir do estímulo gatilho. Nesse contexto, esses estímulos encontram-se dentro do espectro do conjunto de elementos sensoriais do corpo humano, que são as capacidades visuais, táteis, auditivas, gustativas e olfativas (TULVING, 1972).

A informação armazenada pode ser classificada quanto ao prazo, bem como quanto ao tipo de aprendizagem. O prazo pode classificar como memória de trabalho, memória de curto prazo e memória de longo prazo. Já a memória relacionada com o tipo de aprendizagem pode ser classificada como uma memória implícia ou explícita.

As memórias classificadas como explícitas, também encontradas como memórias declarativas em muitas literaturas, são aquelas que memórias que sofrem aquisição quando a pessoa está em um estado de plena consciência, isto é, a memória que é construída a partir de vivências que são claras para a pessoa envolvida no processo, como relatar uma conversa, situações do cotidiano e, desta forma, envolvem acontecimentos que fazem parte da história do indivíduo ou que fazem parte de um quadro histórico geral. As memórias que são relacionadas com fatos históricos ou chamadas de memórias históricas podem ser dividadas 
em memórias autobiográficas ou de acontecimentos gerais ou memórias semânticas (LOMBROSO, 2004).

Por outro lado, as memórias que são macroclassificadas como implícitadas, também chamadas de não-declarativas, são aquelas que têm um processo de aquisição que no qual a pessoa não se encontra em um estado de consciência, isto é, é um processo de aquisição inconsciente, tal como aprender a andar de bicicleta e nunca mais esquecer como realizar essa atividade. É algo intuitivo que simplesmente acontece e que, em geral, envolvem habilidades motoras ou sensoriais que são moldadas a partir do hábito. Não é possível construir um quadro onde seja fácil ou exato na esquematização das etapas que foram empregadas para aquisição de uma memória implícita (IZQUIERDO, 20II).

O diagrama a seguir mostra a taxinomia basica sobre o curso da constituição das memórias explícita e implícita em um cenário de longa duração, assim como as principais regiões acionadas do cérebro.

FIGURA I- Taxonomia dos sistemas de memória de longa duração

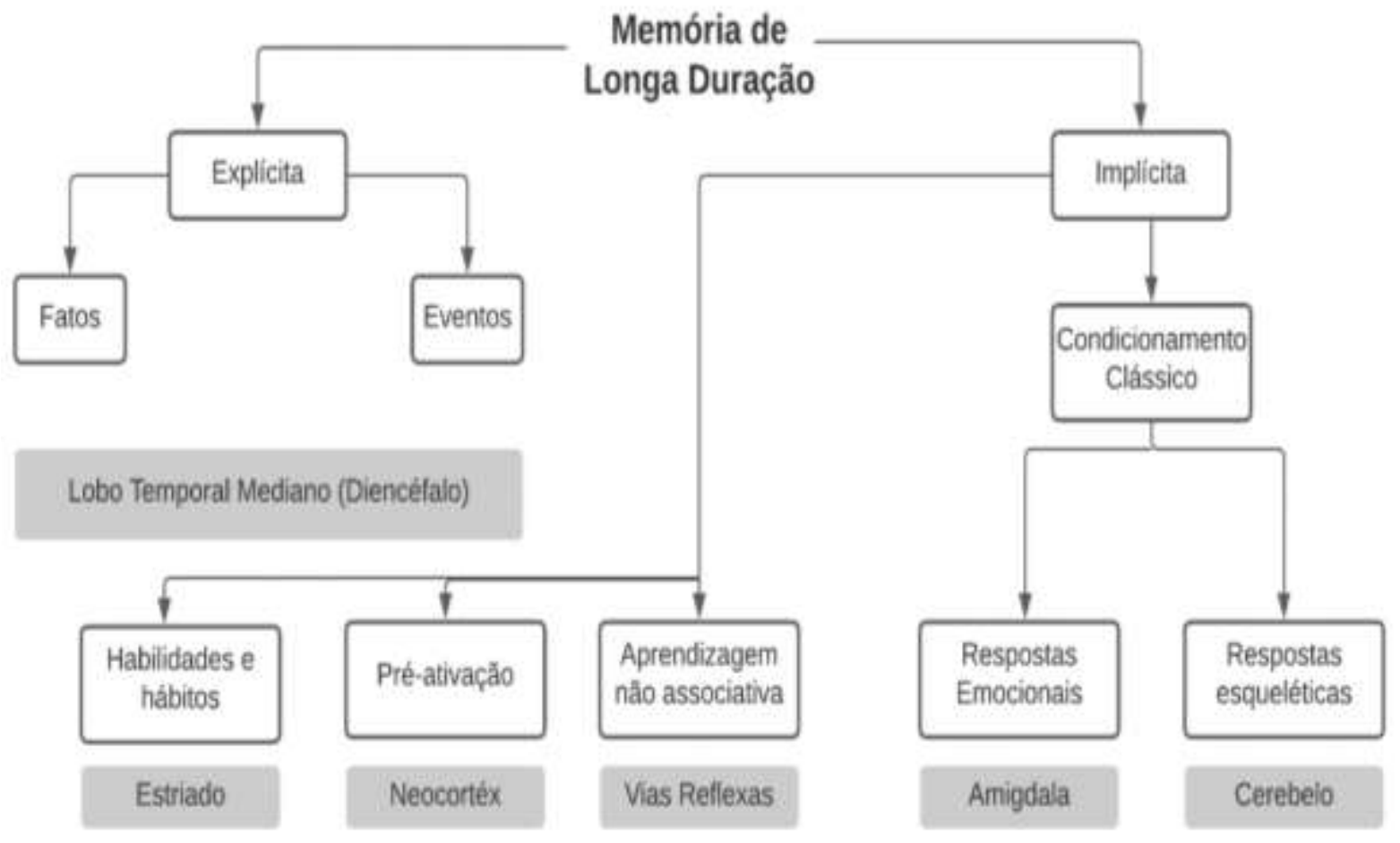

Fonte: Adaptado: SQUIRE; KNOWLTON, 1995 
A classificação da memória quanto a tempo, em termos resumidos, limitam-se ao recorte da duração que a informação fica retida/ armazenada no cérebro. No entanto, para que uma memória seja classificada como memória de longo prazo, inicialmente ela precisa ser de trabalho, de curto prazo e, por meio de um processo de retenção ou esquecimento, torna-se ou não uma memória de longa duração (ATKINSON; SHIFFRIN, I968).

Dessa maneira, a memória representa a aquisição, a formação, a conservação e a evocação de informações. A aquisição é também chamada de aprendizagem, visto que só se "grava" aquilo que foi aprendido (DE AVARENGA DIAS; PESSANHA; DE AGUIAR NICOLARU, 2018).

Tendo em vista em a memória é um porcesso no qual as experiências de um indivíduo levam à modificação do comportamento. $\mathrm{O}$ conceito de atenção pode ser resumido na seleção de informações prioritárias, sendo os processos e mecanismos pelos quais essa selação de fato acontece (HELENE; XAVIER, 2003).

A fica evidente que a atenção é uma função cognitiva complexa. Para Dias e Régis (2018, p. I):

[...] o sujeito filtra as informações que considera como pertinentes ou de seu interesse, através da atenção, mantendo as que se apropriam de significância e sentido de acordo com as suas vivências e meio. Pode-se dizer que o entrelaçamento entre atenção, memória e aprendizagem se evidencia, quando o sujeito mesmo com as suas dificuldades é motivado, através de estímulos criativos e significativos, melhorando os seus resultados e desempenho como um todo.

Nesse contexto, as práticas de meditação permitem que os estudantes fiquem mais atentos ao conteúdo, uma vez que a liberdade cerceada da atividade lúdica mantém o aluno atento ao conteúdo científico atuando na sua zona de desenvolvimento próximo. No caso da emoção, nota-se que a meditação pode deixar nos estudantes marcas emocionais que os ajudam a reconhecer sua capacidade de aprender ciência e torna o conteúdo mais facilmente compreensível e recordável (DA SILVA, 202I).

\section{CONTRIBUIÇÕES DA MEDITAÇÃO EM ÂMBITO ESCOLAR}

O Ministério da Saúde, por meio do Sistema Único de Saúde (SUS), criou um arcabouço de políticas públicas voltadas para inclusão das Práticas Integradas de Saúde 
(PICs). A partir do ano de 20II, a Rede de Atenção Psicossocial (RAPS) foi criada com o dever de prestar atenção a públicos diversos em situações de risco e sofrimento mental, assim como em uso de substâncias viciantes. A partir de 2006, as PICs já estavam reconhecidas no cenário nacional de saúde, tendo participação em diversos níveis de cuidado (BRASIL, 2006).

Percebe-se que as práticas integrativas fazem parte de um grupo de mecanismos integrados de saúde capazes de serem adaptados para diversas realidades, desde à aplicação das PICs para a prevenção e reabilitação em saúde de populações carentes, como preconina a OMS desde o ano de 2005, até a sua transdução para cenários mais dinâmicos e multifacetados, como o ambiente escolar (OLIVEIRA; FREITAS, 2018).

Diversos estudos no espectro da neurociências mostram que atividades como meditação são capazes de liberar substâncias, como o neurotransmissor dopamina, que no seu curso fisiológico causam melhoras em diversos aspectos, gerando sensações prazerosas, aumentando a criatividade das pessoas, levando equilíbrio à mente e criando um ambiente de paz, no qual seja possível desempenhar atividades de forma mais agradável e proveitosa (OLIVEIRA; FREITAS, 2018).

Por meio da evolução do método científico e do desenvolvimento de novas técnicas para a sua instrumentalização, é possível descobrir o comportamento fisiológico de neurotransmissores no ser humano, bem como a sua atuação. É possível comprovar cientificamente como moléculas diversas influenciam as pessoas a partir de diversas situações, sejam elas com a presença da molécula ou exclusão dela, definindo assim a sua função e atuação (SILVERTON, 2017).

Nesse contexto, a meditação faz parte do universo das Práticas Integrativas e Complementares (PICs). Tal prática vem sendo difundida, ganhando mais espaço e visibilidade na sociedade devido aos benefícios que proporciona no organismo humano estudados pelo universo da medicina e da neurociência sobre as relações entre os campos: cognitivo, emocional e físico, apresentando um grande significado para traçar estratégias terapêuticas e de saúde (DENARDO, 2013). Em termos transparemente fisiológicos, os autores Danucalov e Simões (2006, p. 15) destacam que: 
Pesquisas apontam a liberação de serotonina, acetilcolina e dopamina durante a prática meditativa. A dopamina funciona como um importante neurotransmissor de ação rápida do SNC (Sistema Nervoso Central) e sua carência está relacionada ao retraimento social, depressão, déficit de atenção, letargia, dentre outros fatores influenciadores da aprendizagem. Sabendo que a meditação proporciona maior liberação de endorfinas, e de seu baixo custo e simplicidade de aplicação, ela passa a ser uma importante chave para aperfeiçoar a absorção de conhecimento.

A partir dos benefícios cognitivos e emocionais surge a possibilidade de seu uso no ambiente escolar, local em que todo ser humano passa um dia, onde há a formação de valores e hábitos, transformação social, aprendizagem, melhorias na percepção e concentração, que são fundamentais ao ensino, bom rendimento, crescimento pessoal, qualidade de vida e mudança social (COSSIA; DE ANDRADE, 2020).

Os autores Oliveiras e Freitas (2018), justificam a aplicabilidade da prática de meditação dentro do ambiente escolar, uma vez que seus benefícios são sabidamente comprovados, com impacto na aprendizagem escolar, que é um objeto de estudo da pedagogia.

Assim:

[...] formas alternativas de proporcionar melhor educação para as novas gerações são ferramentas constantes de estudos e pesquisas da Pedagogia. A escola é um micropoder, visto como um importante elemento formativo e de transformação social, que interfere diretamente no rendimento e atividade de uma sociedade, pois transforma os indivíduos que nela vivem (FOUCAULT, 1978; LIBÂNEO, 2006 apud OLIVEIRA; FREITAS, 2018, pag. 40I).

Conforme Rocha, Flores e Marques (2015, p. 408):

Meditar proporciona ampliação das capacidades perceptivas e interpretativas, pois envolve contemplação, avaliação e tomada de decisão; amplia o poder criativo e renova o sentido de pertencimento ao coletivo. A meditação é a realização da vida presente, do agora construído historicamente e propicia o autoconhecimento, contribuindo para a formação plena do sujeito.

Os autores evidenciaram diversos benefícios da meditação dentro do ambiente escolar, mostrando que a sua utilizando é urgente para romper com os cânones da educação, trazendo um caráter estimulador, de contemplação e paz para a construção do conhecimento científico. Outros benefícios orbitam no sujeito histórico-crítico que está traçando a sua trajetória à luz de uma conduta metacognitiva, capaz de racionalizar sobre os seus pensamentos ao passo que une as suas instâncias intelectual e afetiva, condizente com a teoria sociointeracionista de Vygotsky as relações entre aprendizagem. 
Segundo Deshmukh (2006), a meditação é capaz, também, de atuar no sistema nervoso autônomo e conduzir a um estado de relaxamento e diminuição do estresse, sendo estados que tornam as pessoas mais pacíficas e dispostas, diminuindo conflitos dentro do ambiente no qual elas convivem.

\section{A MEDITAÇÃO COMO INSTRUMENTO POSSÍVEL PARA O ENSINO DAS CIÊNCIAS}

Formas alternativas de proporcionar melhor educação para as novas gerações são ferramentas constantes de estudos e pesquisas da Pedagogia. A meditação ou mindfulness nas escolas é uma prática cada vez mais comum vista como uma ferramenta importante para reduzir os níveis de stress e ansiedade, assim como para promover a capacidade de concentração.

As crianças que aprendem a meditar na escola têm a capacidade de controlar melhor as suas emoções e de tomar melhores atitudes em determinadas situações. Com efeito, o rendimento escolar aumenta conforme ganham mais experiência nesta prática, bem como a sua capacidade de se concentrar em determinadas tarefas.

Para Freitas e Oliveira (2018, p.I), a medicação dentre do ambiente escolar é um

mecanismo fundamental e que deve ser constantemente trabalhado e aperfeiçoado e dentre sua gama de benefício:

\footnotetext{
O bem estar e aprendizado otimizado com o ato de meditar destes, pode influenciar diretamente na sua formação como pessoa, a qualidade de vida individual e consequentemente dos que mantém contato, maneira na qual interage como profissional, familiar e indivíduo social, e como consequência, modificam a sociedade com suas condutas positivas, gerando evolução e transformações significativas ao país e quem sabe nível mundial.
}

Nesse intuito, Wenzel (2014), indica que aprender química exige do sujeito uma capacidade muito grande de abstração e de imaginação, pois o estudante precisa entender as diferentes representações como modelos teóricos que buscam explicar os fenômenos.

A meditação pode ainda ajudar a desenvolver melhor a criatividade em determinadas tarefas, reconhecer valores importantes para si e para o grupo e dar suporte para lidar com diversos problemas e desafios que interferem na aprendizagem como irritação, ansiedade, 
déficit de atenção - o problema pode não desaparecer, mas a criança passa a lidar com eles de modo mais assertivo e consciente (ROCHA; FLORES; MARQUES, 2015).

O ensino das ciências, muitas vezes, está amparados em técnicas tradicionais e pouco atrativas, que tendem a liberar muitas substâncias, como o cortisol, que se traduzem em estresse generalizado, ansiedade e medo. Nesse cenário, há um bloqueio quanto à aquisição do conhecimento e grandes desafios para os docentes.

A meditação, com o uso de poucos elementos, não é radical, simplesmente utilitária e eficaz. Essa prática dentro do ambiente escolar não deve buscar a delimitação de um esquema de perfeição ou ser imediatista. Fortunado (2020, p. 4) explica a ideia de meditação dentro de um ambiente de ciências, onde:

[...] apresenta-se o ideal de perfeição - bom comportamento, ótimo rendimento - ao mesmo tempo em que se induz aos resultados esperados. A reflexão, o autoconhecimento e o potencial de transformação, por sua vez, são completamente ignorados, embora evidenciados quando se registram os tais sintomas da vida moderna. Dessa forma se despreza o enfoque radical da meditação, reduzindo-a a instrumento de assentimento ao status quo, isto é, a um meio de se ajustar à vida (incluindo a vida escolar) como ela é, sem se dar conta de que poderia ser bem diferente.

Fica evidente que a meditação potencializa não apenas um ambiente externo atrativo, mas um ambiente interno receptivo, que pode ser entendido como uma ressignificação do estudo da química e das ciências exatas na mentalidade dos discentes. A meditação e suas versatilidades devem ser usadas para relaxar, combater o estresse e a ansiedade, bem como aumentar o foco, criatividade e iniciativa de uma forma bidirecional, na qual os discentes e docentes se encontram em sintonia para melhor construir o saber científico.

Entretanto, percebemos que o conhecimento científico das ciências naturais é instrumento para que o sujeito se coloque na posição ativa, capaz de tomar decisões, com a finalidade de contribuir para o desenvolvimento da sociedade (SILVA; AMARAL, 2020).

\section{CONSIDERAÇÕES FINAIS}

As práticas de meditação são técnicas que proporcionam serenidade e plenitude, potencializando o físico, o mental, o emocional e o espiritual do ser. Apesar do âmbito escolar 
ser fragmentado em seus saberes, é possível que novas maneiras de articulação sejam inseridas em sua rotina, de modo que, as crianças integrem as vivências e os diversos saberes de forma significativa e construtiva.

Assim, a meditação torna-se um instrumento de apoio na sala de aula, visto que os programas de mindfulness, apontaram um desenvolvimento a nível cognitivo, social e psicológico dos jovens: na memória, na atenção, nas capacidades académicas, nas capacidades sociais, na regulação emocional e na autoestima.

Em síntese, as informações contidas neste estudo servem como norte para expandir ideias sobre o uso da meditação, no ambiente escolar, em especial no ensino das ciências. Essa visão e possíveis resultados despertam novas discussões e pesquisas a respeito da temática, como instrumento da pedagogia favorável ao aprendizado.

\section{REFERÊNCIAS}

ATKINSON, R. C.; SHIFFRIN, R. M. Human memory: a proposed system and its control processes. In: SPENCE, K. W.; SPENCE, J. T. (Ed.) Psychology of learning and motivation. New York: Academic, 1968. p. 89-195.

BAdDEley, A. D.; ANDERSON, M. C.; EYSENCK, M. W. Memória. Porto Alegre: Artmed, 2011. 472 p.

COSSIA, Tatiana; DE ANDRADE, Maria de Fátima Ramos. Contribuições da meditação em âmbito escolar. INTERFACES DA EDUCAÇÃO, v. II, n. 3I, p. 153-176, 2020.

DANUCALOV; SIMÕES. Neurofisiologia da Meditação. Phorte Editora. 2006.

DA SILVA, Taís Bopp. Atenção e emoções. Letrônica, v. I4, n. 2, p. e38656-e38656, 202I.

DE ALVARENGA DIAS, Fabrizia Miranda; PESSANHA, Renata G. Braga; DE AGUIAR NICOLARU, Cecília Cordeiro Burla. A inter-relação entre memória e aprendizagem. Perspectivas Online: Humanas \& Sociais Aplicadas, v. 8, n. 21, 2018.

DESHMUKH, V. D. Neuroscience of meditation. TSW Holistic Health and Medicine, Florida, v.I, p. 275-289, Nov. 2006.

DIAS, FABRIZIA M. DE A.; RÉGIS, GLAUCE VM. O Entrelaçamento entre atenção, memória e aprendizagem. Perspectivas Online: Humanas \& Sociais Aplicadas, v. 8, n. 22, 2018. 
DOS SANTOS, Rossie Katherine; ALBERTON, Taila; COUTINHO, Tatiane Sueli. A MEDITAÇÃO COMO FERRAMENTA AUXILIAR NO CONTROLE DO ESTRESSE. Anais da Semana de Formação Acadêmica e Científica e Cultural e Humanística (FACCHU), v. I, n. I, 2019.

FORTUNATO, I. Coisas que gostaria de trabalhar na formação de professores de ciências e matemática, mas não sei como. Revista Internacional de Pesquisa em Didática das Ciências e Matemática, v. I, p. e020013-e020013, 2020.

FOUCAULT, M. Microfísica do Poder. Paz\&Terra. 1978.

FREITAS, N. A.; OLIVEIRA, V. M. M. Contribuições da meditação na concentração e percepção no contexto da aprendizagem em escolares do ensino médio. 2018, p. 1-388-416.

HELENE, A. F.; XAVIER, G. F. A construção da atenção a partir da memória. Brazilian Journal of Psychiatry, v. 25, p. 12-20, 2003.

LIBÂAEO, J. C. Didática. Cortez Editora. 2006.

ROCHA, Mariana Duarte; FLORES, José Francisco; MARQUES, Luciana Fernandes. Fundamentos da meditação no ensino básico: transdisciplinaridade, holística e educação integral. Revista Terceiro Incluído, v. 5, n. 2, p. 398-413, 2015.

SILVERTORN, D. Fisiologia Humana: Uma Abordagem integrada. Sétima Edição. Artmed. 2017 .

SILVA, R. S. Experimentação no Ensino de Química: Uma Sequência Didática Sobre a Formação Da Ferrugem. REAMEC - Rede Amazônica de Educação em Ciências e Matemática, [S. l.], v. 9, n. 2, p. e21058, 2021.

SILVA, Rafael Soares. Um jogo didático para o ensino de equilíbrio químico. Revista Amor Mundi, v. 2, n. I, p. 31-39, 202I.

SILVA, Rafael Soares. As aplicações da informática no ensino de química como alternativa para o ensino e aprendizagem. Revista Amor Mundi, v. I, n. 2, p. 43-56, 2020.

SILVA, Rafael Soares; AMARAL, Carmem Lúcia Costa. A Educação Inclusiva no Ensino de Ciências e Matemática: Um Mapeamento na Revista Educação Especial no Período de 2000 a 2018. Communitas, v. 4, n. 7, p. 28I-294, 2020.

SILVA, Rafael Soares; AMARAL, Carmem Lúcia Costa. Percepção de professores de química face à educação de alunos com deficiência visual: dificuldades e desafios. South American Journal of Basic Education, Technical and Technological, v. 7, n. I, p. I08-I29, 2020. 
SQUIRE, L.R, KNOWLTON, B.J. Memory, hippocampus, and brain systems. In: Gazzaniga MS, editor. The cognitive neurosciences. Cambridge: A Bradford Book; 1995. p. $825-37$.

TULVING, E. Episodic and semantic memory. In: TULVING, E.; DONALDSON, W. Organization of memory. New York: Academic, 1972, p. 381-402.

ZQUIERDO, I. Memória. 2. ed. Porto Alegre: Artmed, 20II. I33 p.

YUS, Rafael. Educação Integral uma educação holística para o século XXI. Trad, Daisy Vaz de Moraes. - Porto Alegre: Artmed, 2002.

WENZEL, J. S. A Escrita em processos interativos: ( $R$ e)significando conceitos e a prática pedagógica em aulas de química. Curitiba: Appris, 2014. 